Carcinoma spreads from the penis to the inguinal glands by lymphatic embolism. This is fortunate, for the operation of amputation of the penis can, in consequence, completely excise the primary growth and thus secure the patient from any risk of local recurrence. If the inguinal glands have not been involved the operation would cure the patient, but if the inguinal glands are already involved the operation would at least save the patient from the horrors of a fungating growth of the penis.

\section{BIBLIOGRAPHY}

CADE, S. (1939), Proc. R. Soc. Med., 33, 1509.

COORAY, G. H. (1944), Indian F. Med. Res., 32, 71 .

DEAN, A. L. (1950), 'A Text Book of Surgery,' edited by Christopher. W. Saunders \& Co., Philadelphia, p. 131 r.B.
DAVIES COLLEY, cited by Pearce Gould.

GALBRAITH, W. W. (1948), "Textbook of Genito-Urinary Surgery,' edited by Winsbury White. E. \& S. Livingstone, Edinburgh, p. 609 .

HILTON, cited by Pearce Gould.

JACOBSON, W. H. A. (1893), 'The Diseases of the Male Organs of Generation.' J. \& A. Churchill, London, p. 707

LEHMANN, cited by Ngai.

MCCREA (1940), 'Diseases of the Urethra and Penis.' John $\stackrel{\vec{F}}{\rightarrow}$ Wright \& Sons, Ltd., Bristol, p. 27 r.

NGAI, S. K. (1933), Amer. F. Cancer, 19, 259.

PAUL, M. (1929), Fournal of the Ceylon Branch of the Brit. Med. Assoc., 26, No. 2, p. 13.

PEARCE GOULD, A. (1882), Lancet, May 20, 821 .

THIERSOH, cited by Pearce Gould.

WOLBARST, A. L. (1932), Lancet, i, I 50.

WINDEYER, B. W. (1939), Proc. R.'Soc. Med., 32, 1504 की

WINSBURY' WHITE, H. B. (1948), "Textbook of GenitoUrinary Surgery.' E. \& S. Livingstone, Edinburgh.

THOMSON-WALKER, J. (I936), 'Genito-Urinary Surgery.' Cassel and Company, 'Ltd., London.

\title{
SIMPLE OBESITY
}

\author{
By John S. Richardson, M.V.O., M.D., F.R.C.P. \\ Physician, St. Thomas's Hospital
}

The interest that our forebears had in obesity was social rather than medical. It was displayed in its more flamboyant form by the voluptuaries of some of the ruling houses of Europe and painters of the School of Titian and Rubens, who delighted in mastering the shadows cast by massive folds of flesh. It also appealed to the sporting instincts of the inhabitants of this country who love records that can be numerically expressed.

The present desire of most people to avoid obesity reflects not only an alteration in taste and the present dictates of fashion, but also shows an awakening to some unpleasant realities. Insurance statistics, largely those of the Metropolitan Life Insurance Company of America, show that between the ages of forty-five and fifty for every Io $\mathrm{lb}$. overweight there is roughly a ro per cent. increase in the death rate over the average for that age. This is largely a result of cardiovascular and renal disease, whilst fat diabetics have a very much poorer outlook than thin. Age certainly contributes to the incidence of these disorders in the obese, but the evidence of the dangers of obesity is overwhelming. The problem is, therefore, quite literally a vital one.

\section{Physiological Considerations}

Physiologists have tackled it for many years from numerous aspects and a great deal of work has been done. Nevertheless, it is fair to say that up to now all metabolic studies have failed to shof why some get enormously obese and others remain slim all their lives. It seems clear that in the obese food is no less efficiently absorbed than in the normal. It is not converted into fat or stored more easily, neither is it mobilized less easily, nor burnt more economically. Recently Dodds (I950) reported some experiments by which he has examined this subject. He found that when some people whose weights have been constant over many years were given double or treble their normal intake, they did not put on weight. $\mathrm{He}$ showed that in them this was not due to a failure of assimilation or digestion, but suggested that some studies that were being made in his department on their respiratory metabolism might show that they responded to a high caloric intake by an increase in their metabolic rate. The control series of those who got fat with this gross overfeeding showed no such increase in metabolism. These observations call to mind the theory of 'Luxus Konsumption'.(Grafe and Graham, I9II; N Grafe, 1933) which has long been in disrepute, $N$ Wiley and Newburgh (193I) finding no evidence 은 to support it. Dodds (1950) made the novel $\omega$ suggestion that the mechanism that keeps most people's weight so remarkably constant was the $\stackrel{\varrho}{\leftarrow}$ gravitational pull of the earth, but he has so far $\mathbb{D}$ been unable to devise experiments to test his hypothesis. 


\section{Fluid Retention}

The emphasis that different workers place on the importance of fluid retention in obesity varies considerably, but most are agreed that obese people tend to retain fluid more easily than slim. Greene (1950), who stresses the importance of fluid retention, has pointed out that pitting oedema in the legs is common in obese women in the absence of renal or cardiac lesions, and oedema only appears when a considerable amount of fluid has been retained.

It is possible that in some of these cases the "oedema is due to hypostatic causes and a poor venous return, as pitting oedema, when the weather is hot or after standing, is sometimes found in women with large legs, even if they are otherwise slim.

It is commonplace to find that delay in apparent reduction in weight in a patient on a very low calorie diet is due to fluid retention (Newburgh, 1942). Diuretics, long used in the treatment of obesity, result in a very rapid fall in weight to the expected weight level. This diuresis will occur spontaneously, but its delay may well discourage the patient so much that the strict limitation of food intake is given up and the treatment abandoned.

Extra-cellular fluid retention is not present in every case of obesity, as Odier and Mach (1949), after measuring the extra-cellular fluid in 43 clinically obese patients by the sodium thiocyanate method (Crandall and Anderson, 1934), found it was actually less than in the 20 controls of normal size.

McCance and Widdowson (I95I) have recently devised a method of estimating the total body fat. They determined the extra-cellular fluid volume and the total body water. The difference between these figures was regarded as the cellular water; that in turn was assumed to be 67 per cent. of the weight of the cellular mass. The body fat was calculated by subtracting the weight of the extracellular fluid, the cell mass and mineral from the body weight. They found that both the extracellular fluid and the fluid mass, when expressed as a percentage of the body weight, were less in obese men and women than in the normal. They showed, therefore, that obesity in their subjects was due to an increase in fat and not to an increase in extra-cellular water or cellular mass, 67 per cent. of which is intra-cellular fluid. The percentage of fat was higher in normal women than in men and was between 12.6 to 28.5 per cent. and 7.2 to 22.4 per cent. respectively. The obese women contained up to 58 .I per cent. of fat.

Hormones such as thyroxine, oestrogens and certain adrenal steroids have an effect on fluid balance, the last two leading to fluid retention and the first to diuresis. These factors play an important part in endocrine disorders such as myxoedema, the menopause and in some cases of hyperfunction of the adrenal cortex or therapeutic over-dosage from desoxycorticosterone, but their role in simple obesity is at present believed to be secondary and of no great importance. The hormone that is probably of much more significance in fluid retention in obesity is the posterior pituitary anti-diuretic hormone. Verney (1946) has shown that not only trauma but also emotional stress, by acting on the hypothalamus, can lead to a release of the anti-diuretic hormone, with consequent fluid retention. $\mathrm{He}$ suggested that circumstances in which sympathetic tone is low in man might be favourable to the prolonged secretion of the hormone.

It is felt that, while recognition of fluid retention is of some importance in the management of obesity, this importance should not be overstressed.

\section{Adipose Tissue and its Distribution}

There is no good evidence that the metabolism of adipose tissue in the obese is in any way different from that in people of normal weight (Newburgh, 1944). Likewise, no anatomical abnormalities have been found in the structure of adipose tissue. Edwards (195 Ib) has shown that fat spaces in the cells of fatty tissue in the obese are larger in proportion to the degree of obesity when this is of the simple type, but, when the case is one of lipomatosis, fat spaces in the cells are of normal size but the cells are present in abnormal numbers. $\mathrm{He}$ has also done interesting work on the distribution of subcutaneous fat (Edwards, 1950). $\mathrm{He}$ estimated this by measuring the thickness of folds of skin and subcutaneous tissue at 53 standard sites over one side of the body in various age groups and in the two sexes. The normal pattern shows a sparing of the extremities with a greater thickness over the shoulders and base of the neck, the pituitary hump, the back, abdomen and thighs. Sacral and adductor pads, pads over the lower angle of the scapula, the so-called pituitary cape, and pads behind the knees are found in slim people and are variations of the normal fat pattern. This constancy of pattern of subcutaneous fatty tissue is maintained in the obese and there is very little difference in the fat pattern between them and the slim. This is of special interest, as the great popularity of the endocrine theories of obesity in the past led to various descriptions of so-called pituitary, adrenal, thyroid and hypogonadal body shapes. It has been realized for some years that these body patterns are found in many patients in whom there is no evidence of any endocrine disorder and it is now recognized that they merely 
represent the different ways that people can get fat and are of little or no diagnostic significance. Edwards (I95 Ia) has shown that this pattern of distribution of subcutaneous fat is the same in pre-pubertal boys and girls, but that once puberty is established differences develop. These are not of any very great degree and the chief difference in distribution is to be found in the legs, that have I.25 times as much fat in them in proportion to the total fat in females as in males. Females of average weight of all ages have approximately 1.7 times as great an average thickness of subcutaneous fat as have males.

\section{Endrocrine Glands}

The belief in the simple relationship of the endocrine glands to obesity, like other simple conceptions of this problem, has not survived an increase in knowledge, but it is unwise to assert, as some do, that their influence is entirely unimportant. Simpson (1952) has recently summarized some of the evidence in favour of the thesis of an endocrine origin for obesity and draws attention to Kendall's (r945) work on the adrenal steroids. Kendall showed that Compound (A) (II dehydrocorticosterone), when implanted into mice, produced an increase in weight, although the animals were maintained on a standardized diet. When the carcases of these rats were analyzed the increase in weight was shown to be due to fat and the body protein was reduced. In order to explain this, Kendall (1945) suggested that the action of certain adrenal steroids resulted in glucose derived from protein being converted into fat. Simpson (1952) points out that Kendall, by this experiment, has shown than an endocrine substance exogenously supplied can lead to an increase in weight without the animal having an increase in calories supplied to it.

Insulin plays a large part in fat metabolism. It allows the transformation of glucose into fatty acids and permits these fatty acids to be stored in the fat depots of the body. When there is no insulin in the body the conversion of dietary glucose into fat is reduced to ro per cent. of the normal rate (Stetten and Boxer, 1944; Brady et al., 195I; Chernick and Chaikoff, I95I).

The anterior pituitary gland has an effect on body weight through the growth hormone. Young (195I) has shown that the administration of growth hormone to dogs, with or without insulin, results in the maintenance of their body weight when they were kept on a diet that was of insufficient caloric value to do so. This was achieved by the deposition of protein and the burning of fat with the consequent production of more energy. When more food was allowed to his animals both protein and fat were stored. These recent observations are of very considerable interest, but their relationship to the problems of simple obesity in clinical practice is still obscure.

\section{Hypothalamus}

The original observation of Erdheim (1904) that lesions of the hypothalamus rather than of the hypophysis lead to obesity received experimental support in 1913 when Camus and Roussy showed that hypophysectomy in dogs did not cause obesity unless the hypothalamus was also damaged. Hetherington and Ranson (1939), Brobeck et al. (1943) and, more recently, Kennedy (1950 and I95 I) have confirmed this by use of a technique whereby small electrodes are introduced into the hypothalamus and electrolytic lesions produced. The technique is a delicate one, as the hypothalamus in a rat, the animal that is usually used, is only $3 \mathrm{~mm}$. across. Rats so treated all developed marked obesity and this is the result of an enormouse increase in their appetite and not due to increased absorption or utilization. Some of Kennedy's rats had weights that were double those of the controls and they contained as much as 65 per cent. of fat. The animals showed no increase in skeletal length and Kennedy suggests that this can be taken to show that the increase in weight was not due to any anterior pituitary factoro The figure of 65 per cent. is particularly interest ing, as recently Widdowson and McCance (r95 I have recorded the case of a woman of 25 stone who, by their methods, was shown to contain over 60 per cent. of fat.

Hetherington and Ranson (1939) and Brobeck et al. (1943) found that when food was given ad libitum to their operated rats the amount of increase in weight was accounted for completely by the amount of food eaten, but that in a small proportion of the rats whose food was restrịcted after operation there was a minor increase in weight over the controls, suggesting that in them a mechanism other than increased intake was present. This may be explained by the change in the feeding habits of these animals that follows operation and leads them to eat whatever is available as fast as they can. Brobeck et al. (1943) have shown that normal rats will convert glucose into fat at an accelerated rate if the animals are trained to eat their normal 24 hours' ration in a short time. Kennedy's observations on this alteration in feeding habits are of considerable interest. His animals, like those of previous workers, showed a violent and voracious appetite even before they were completely round from the anaesthetic. This voraciousness became less after the effects of the operation had worn off, but they would still eat two or three times as much as the controls. Once their obesity was fully developed their food 
intake dropped and Kennedy found that some of his rats could maintain a weight of some 50 per cent. above the normal for an indefinite period without any significant increase in intake of food. This observation agrees well with those of clinicians and dietitians who have frequently observed that once patients have become obese they need not eat more than a normal person in order to maintain their weight and may in fact eat less, as their activity is perforce reduced and their intake is enough for their energy requirements.

Kennedy's rats showed a remarkable change in their attitude to food once the period of gorging was over. The normal rat eats anything and the only limiting factor seems to be its caloric requirements. The hypothalamic animal, once it is obese, becomes discriminating. Kennedy showed this by mixing kaolin with the feeds and, while the normal animals ate an amount that would supply their caloric requirements, the obese animals refused to eat the mixture until they had used up their fats stores. If the ordinary unmixed diet was restored to them the rats would again eat enormously until they were once more grossly obese, just as they had after recovery from the operation.

Dehydration will also reduce the amount that operated rats will eat, and their appetite at once improves when fluid is supplied to them. It thus seems that, in these animals, reduction in palatability of their food and the withholding of fluid can both lead to a restriction in their appetite, but that once a desirable diet is restored they will eat themselves into a state of obesity once more.

These findings throw light on clinical observations of obese patients. It is generally agreed that fluid retention and diuresis is responsible for the very rapid changes in weight that are found in some obese patients. Kennedy suggests that the temporary success of dehydration therapy may, in part at least, be due to its anorexic effect. Certain it is that reducing regimes that rely on dehydration without any attempt at producing permanent control of the appetite are effective for only as long as the patient remains on them. The reduction of appetite in the obese rats when given unappetising food also has its parallel in man. Very few people enjoy a reducing diet, however unrestricted their purse, and they will have to face the fact that the success of the treatment will largely depend on the reduction of their appetite, and that this will involve some loss of interest in the delights of the table. If they remain on a reducing diet for a sufficient length of time their appetite and eating habits, as well as their interest in food will change and it will be possible for them to maintain a reasonable weight without undue hardship. If they come off the diet too soon they will, like the rats, begin to eat too much of the food they like and again become obese. Patients have a harder time than the rats, as their gift of free will makes the struggle to control their appetite their own, whereas the rat has his food problem settled for him under the conditions of the experiment. This is why it is useful to have some patients under strict in-patient control at the beginning of treatment. The rapid initial reduction that is then possible and the discipline that is forced upon them results in encouragement and eventually in an alteration of appetite that may enable them to stick to their diet long enough to develop a change in eating habits.

Kennedy has suggested that in his rats the normal mechanism of appetite control is exercised through the hypothalamus and results in the animals eating only enough for their caloric requirements. In those who have had an induced hypothalamic lesion this control is absent or imperfect and such control as exists is supplied at the cortical level and, as a result, the rat will not eat unpalatable food. He tentatively suggests that the same miy be true of man, lean people having a perfectly geared hypothalamic mechanism, whereas those who tend to obesity have to rely more and more on cortical control. Thiso theory accords well with both experimental and clinical evidence and leads us to the consideration of the effects of disorders of the psyche on the problems of obesity.

\section{Psychological Factors}

The importance of psychological factors in the production of obesity has been appreciated to an increasing degree over the last decade and, as a result, this aspect of the subject has been studied by those interested in pscyhosomatic medicine (Weiss and English, 1943; Dunbar, 1943) and by psycho-analytical methods (Fenichel, I945). Bruch (1940) stressed the importance of psychological factors in obesity in childhood and emphasized in particular the lack of parental love that is sumetimes shown to these children. Their mothers unconsciously try to make up for their lack of affection by over-indulging and over-protecting the child and the child himself may find solace for the love he misses and gain a feeling of security in over-eating.

The success of the practical application of Bruch's observations has been reported by several authors, and Macaulay (I95I) has recorded a good example in an obese girl in whom he showed that fluid retention was an unimportant factor. I have recently been less successful with a young girl. She and her brother, aged thirteen and twelve, respectively, were quite amazingly alike in appear- 
ance, with a similar fat distribution and like firm consistency of their adipose areas. They were put on the same reducing diet, given the same instructions and exhortations and both attended the Dietetic Department of St. Thomas's Hospital regularly. The boy lost weight rapidly and without apparent effort. The girl lost very little and said she was always hungry. It was quite obvious that the boy was his mother's favourite and that she had little sympathy for or interest in her daughter. All our efforts to educate the mother were unavailing and every attempt to persuade the girl to co-operate was met by a smiling, goodtempered but very definite assertion that she could not stick to her diet, she did not like it and was always hungry. This attitude is frequently found in adults who eat to gratify not only their appetite for food, but also to recompense themselves for failures in life, for sexual frustrations and the neglect of others. Some actually take pride in their obesity, as in it they find a distinction that is granted to them in no other way.

Fear, as in all human affairs, has a predominant place in the production of obesity. Fear makes the mother urge her child to eat so as to avoid the dangers of illness, and any falling off of his appetite is regarded with horror. Fear of not getting enough leads some patients who have been hungry in childhood to eat whenever there is a chance. Fear of social failure may result in a desire to avoid any situation that might result in humiliation, and over-eating is then used not only to compensate for other delights that are missed, but the result-obesity itself-provides an excuse for not competing. Failure is thus used by the patient in an attempt to avoid failure.

There are several series of carefully studied cases of obesity in which it has been found to be commonly associated with insecurity and tension. Schopbach and Matthews (I945) studied 50 cases, in all but six of whom psychogenic factors seemed closely related to the onset of obesity. They were for the most part suffering from mild anxiety states in which obsessional features were predominant. A further 50 obese patients were studied by Freed (1947), who found good evidence that anything that increased their emotional tone led to a coincident increase in appetite. Not only prolonged anxiety, but severe emotional trauma of a sudden and violent nature can lead to the development of obesity. Shorvon and Richardson (1949) reported three cases that, with many others not included in the report, illustrated the horrifying stresses to which these apparently placid and certainly obese people had been subjected. The presence of powerful emotional factors in them was originally suspected only when the patients failed to lose weight on dietary restriction under satisfactory supervision. Excitatory abreactions were induced by the ether technique and the patients re-lived the original traumatizing situation. The release of tension that followed this resulted in loss of anxiety and in most cases an actual loss of weight of between $I$ and 2 stones. After this treatment further attempts at reduction in weight were made using the dietary regime that had previously failed but was now successful.

Obesity resulting from severe and sudden psychological trauma was observed by Lichtwitz (1923) in the first and Gilbert-Dreyfus (1948) in the second world war. It occurred in women who were subjected to severe mental strain and resulted from bombing, imprisonment, death of a husband or brother, or some other acute stress of war.

Hochman (1938) reported six cases in whom a shock, such as a death of a parent, had resulted in over-eating, and Greene (1946) recorded a case in whom great unhappiness led to obesity that disappeared when her life became smooth again, in spite of the fact that the patient gave up her diet at the same time.

The discussion earlier in this short review will have shown that there is a background of physiological observations that are consonant with these psychological ones. The work on the hypothalamus in the production of obesity through alteration of appetite, and Verney's (1946) observations on the effect of emotion acting through the hypo-? thalamus on the anti-diuretic hormone may clearly be relevant. Certainly in the field of practice the treatment of obesity resolves itself into devising methods that will induce a control of appetite with a consequent reduction of caloric intake. This is predominantly a psychological problem that requires individual study in every case. The social circumstances of the patient must be examined, if possible modified, and the emotional reactions of the individuals to their life situation must be appreciated and help given on that level when it can be. The attitude of the doctor and the dietitian to the patient is all-important, and the correct balance of encouragement and criticism must be achieved.

\section{Summary}

While the proper treatment of obesity is at the present time agreed by all to be the reduction of caloric intake, and this requires the control and, if possible, the alteration of appetite, the reason why many people get obese and others always remain slim is by no means established. The answer does not lie in all cases in a simple statement that the obese eat too much and the slim too little, as Dodds (I950) has shown by the persistence of slimness in his subjęcts who were given two or three times 
their normal caloric requirement. It seems there must be some mechanism that normally maintains the body weight at a remarkably constant level, but this is not as yet understood. Where obesity and slimness are undoubtedly related to caloric intake, and this is in the vast majority of cases, the theory that suggests that appetite control may be a combined function of the hypothalamus and cortex is the most satisfactory. Damage to or dysfunction of the hypothalamus leaves only cortical control, and man being what he is, that control may break under various stresses and result in anorexia or more often in over-eating.

\section{BLBLIOGRAPHY}

BRADY, R. O., LUKENS, F. D. W., and GURIN, S. (195r), Science, II3, 413.

BROBECK, J. R., TEPPERMAN, J., and LONG, C. N. H. (1943), Yale f.' Biol.' 'E Med., r5, $83 \mathrm{I}$.

BRUCH, H. (1940), Amer. F. Dis. Child., 59, 739.

CAMUS, J., and ROUSSY, G. (1913), C.R. Soc. Biol. Paris, 75, 483.

CHERNICK, S. S., and CHAIKOFF, I. L. (1951), f. Biol. Chem., 188, 389.

CRANDALL, L. A., JUN., and ANDERSON, M. X. (1934), Amer. F. Digest. Dis., $1,126$.

DODDS, E. C. (1950), Proc. Roy. Soc. Med., 43, 342.

DUNBAR, F. (1943), 'Psychosomatic Diagnosis,' Hoeber, New York.

EDWARDS, D. A. W. (1950), Clin. Sci., 9, 259.

EDWARDS, D. A. W. (1951a), Proc. Roy. Soc. Med., 44, 904.

EDWARDS, D. A. W. (195 rb), Clin. Sci., ro, 305 and 317.

ERDHEIM, J. (1904), S.B. Akad. Wiss. Wien., I13, 537.

FENICHEL, O. (1945), 'The Psycho-analytic Theory of Neurosis,' Norton, New York.
FREED, S. C. (1947), F. Amer. Med. Ass., 133, 369.

GILBERT-DREYFUS (1948), Pr. Méd., 56, 249.

GRAFE, E. (1933), ' Metabolic Diseases' and their Treatment,' Lea \& Febiger, Philadelphia.

GRAFE, E., and GRAHAM, D. (1911), Ztschr. f. Physiol. Chem., 73, $I$.

GREENE, R. (1946), Postgraduate Medical Journal, 22, 169 GREENE, R. (1950), Proc. Roy. Soc. Med., 43, 344.

HETHERINGTON, A. W., and RANSON, S. W. (1939), Proc. Soc. Exp. Biol., N.Y., 41, 465 .

HOCHMAN, S. (1938), Med. Rec., N.Y., 148, 108.

KENDALL, E. C. (1945), Trans. Josiah Macy Foundation Conference on 'Metabolic Aspects of Convalescence,' N.Y., roth meeting, $8 \mathrm{r}$.

KENNEDY, G. C. (1950), Proc. Roy. Soc. B., 137, 535.

KENNEDY, G. C. (1951), Proc. Roy. Soc. Med., 44, 899.

LICHTWITZ, L. (1923), Klin. Wschr., 2, 1255.

MACAULAY, D. (1951), Arch. Dis. Childhood, 26, 539.

MCCANCE, R. A., and WIDDOWSON, E.M. (195I), Proc. Roy. Soc. B., 138, I 15 .

NEWBURGH, L. H. (1942), Arch. Intern. Med., 70, 1033.

NEWBURGH, L. H. (1944), Physiol. Rev., 24, 18.

ODIER, J., and MACH, R. S. (1949), Praxis (Rev. Suisse Med.), 38, 834 .

SCHOPBACH, R. R., and MATTHEWS, R. A. (1945), Arch. Neurol. Psychiat., Chicago, 54, 157.

SHORVON, H. J., and RICHARDSON, J. S. (1949), Brit. med. F. 2, 95 I.

SIMPSON, S. L. (1952), Brit. Med. F., i, 476r.

STETTEN, DE W., JUN., and BOXER, G. E. (1944), F. Biol. Chem., I56, 27 I.

VERNEY, E. B. (1946), Lancet, ii, 739 and 781.

WEISS, E., and ENGLISH, O. S. (1943), 'Psychosomatic Medicine,' Saunders, Philadelphia.

WIDDOWSON, E. M., and McCANCE, R. A. (195I), Proc. Roy. Soc. Med., 44, 903.

WILEY, F. H., and NEWBURGH, L. H. (1931), f. Clin. Invest. 10, 733 .

YOUNG, F. G. (1951), Brit. med. F., ii, 1167 .

\title{
CONVULSIONS IN INFANCY AND CHILDHOOD
}

\author{
By R. M. Mayon-White, M.D., Ph.D., M.R.C.P., D.C.H. \\ Paediatrician, Ipswich Area, East Anglian Regional Hospital Board
}

To a mother the word ' convulsion' seems to mean almost any sudden temporary aberration from what she believes to be normal childish behaviour. The complaint of 'convulsions' in a child may cover simple starts and stares, crying spells, tooth-grinding, colic pain, temper tantrums, epilepsy in any of its forms, nightmares in a school child, or the Moro start reflex of a baby. The first task in such a case is to elucidate a description of the event and so define the term. For our present purpose no better definition could be found than that given by Hughlings Jackson: 'A convulsion is the product of sudden temporary nervous discharges.' Jackson was at pains to emphasize the importance of each of the adjectives he chose. Some 50 years later the electroencephalogram, whilst increasing our knowledge of epilepsy, served to substantiate the validity of Jackson's concept so that the definition serves equally well today.

The definition 'sudden temporary nervous discharges' adequately describes the observed phenomena of epileptic seizures; it may also be said to cover the psychogenic discharges resulting in hysterical fits, breath-holding attacks and temper tantrums; it covers the state of increased irritability of nerve cells during pathological alterations of the physiological milieux interieur-tetany, for example - or affected by toxins either endogenous (uraemia), exogenous (lead encephalopathy) or bacterial (tetanus). Without stretching the point too far, even simple faints are covered by the definition, for the modern use of the term vasovagal syncope indicates that we recognize overaction of the parasympathetic as the aetiological factor. 